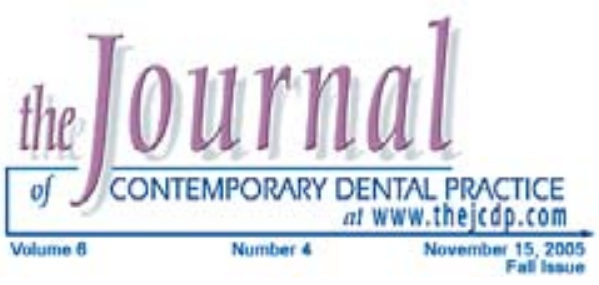

\title{
Retention of Maxillary Molars with Class III Furcation Involvement Utilizing Glass-Ionomer: Two Case Reports
}

\author{
Krishnanjaneya Pathakota Reddy, BDS; Dilip Gopinath Nayak, MDS; \\ Ashita Sadananda Uppoor A, MDS
}

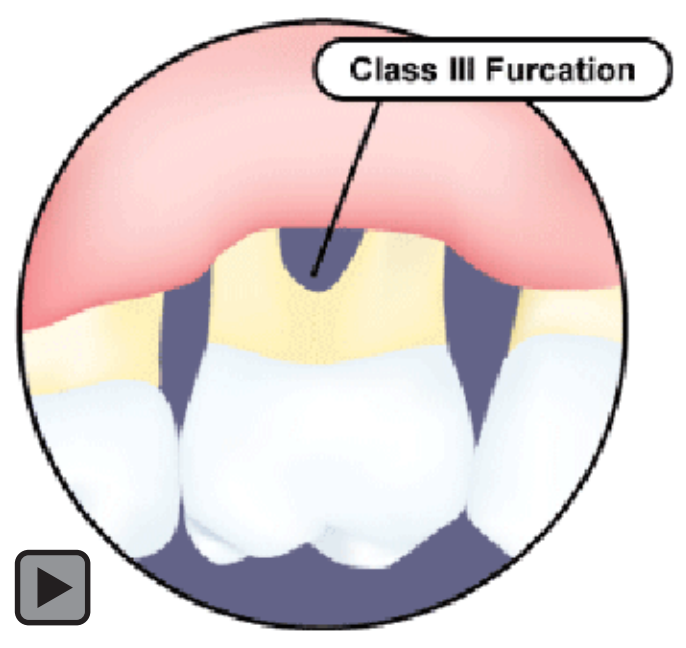

\section{Abstract}

Advanced furcation invasion has long been a treatment dilemma for the clinician. The present two case reports used a glass ionomer restorative material as a barrier in the treatment of maxillary Class III furcation defects. One year follow-up results showed a reduction in tooth mobility and probing depths and no bleeding on probing with the use of the glass ionomer. These case reports offer another option in the treatment of a seemingly hopeless periodontally involved maxillary molar.

Keywords: Glass ionomer, permanent, furcation therapy, molar, dental materials

Citation: Reddy KP, Nayak DG, Uppoor A AS. Retention of Maxillary Molars with Class III Furcation Involvement Utilizing Glass-lonomer: Two Case Reports. J Contemp Dent Pract 2005 November; (6) 4:160-167.

(C) Seer Publishing 


\section{Introduction}

Treatment of Class III furcation ${ }^{1}$ has historically been less than predictable. Long-term studies have demonstrated poor survival rates of teeth with advanced furcation involvement. ${ }^{2,3,4}$ Although multiple treatment modalities have been attempted to retain teeth with severe furcation invasion, clinical success has not been predictable. Treatment attempts range from non-surgical therapy ${ }^{1}$, furcation obliteration, surgery to increase access to the furcation ${ }^{5}$, root resections $^{6,7}$, tunnel procedure ${ }^{8}$, guided tissue regeneration ${ }^{9,10,11,12}$, and a combination of graft materials, membranes, and coronally positioned flaps. $^{13,14,15,16}$

Regenerative techniques that have been successful in the treatment of Class II mandibular furcation involvements have been less predictable when performed in Class III situations. ${ }^{17}$ In the past restorative materials have been used to obliterate furcation; the goal was to improve plaque control by eliminating the anatomic niches within the furcation where bacteria can accumulate. Also, in the past polymeric reinforced zinc oxide-eugenol (IRM), amalgam, glass ionomer, and resin ionomer restorative materials were utilized to fill Class III furcation invasions. ${ }^{18,19,20,21}$

Van Swol and coworkers ${ }^{18}$ compared amalgam, zinc oxyphosphate cement, and glass ionomer in the treatment of surgically created furcation in non-human primates. Radiographs taken at various time intervals demonstrated radiolucency with all materials utilized. Glass ionomer produced only slight radiolucent changes that were less likely to progress with time. The authors reported the greatest biocompatibility with glass ionomer via histological evaluation. Scherer and Drago ${ }^{22}$ utilized modified resinionomer restorations into subgingival locations and attempted to delineate ideal characteristics of a material used in this manner. A follow-up study by Dragoo ${ }^{23}$ suggested histologic evidence of epithelial and connective tissue adherence to the resin-ionomer restorative materials utilized subgingivally. The author reported the gingival tissues tolerated the material well and felt resinionomers possess biocompatibility with the periodontium. In case reports by White $\mathrm{Jr}{ }^{24}$ and Breault et al. ${ }^{25}$ resin and resin-ionomers were placed subgingivally to repair areas of root resorption. Breault et al. ${ }^{26}$ utilized resin-ionomers to treat maxillary Class II furcations and an abfraction.

In the present two case reports a glass ionomer restorative material [GC Fuji II, GC Corporation, Tokyo, Japan] was used as an occlusive barrier in the treatment of multi-furcated maxillary molars.

\section{Case Report}

\section{Case 1}

A 50-year old male patient presented with Class III furcation defects involving all three furcations in both the maxillary first molars. ${ }^{1}$ Both teeth had in common a "poor to hopeless" prognosis, based on the clinical parameters of Grade II mobility, probing depths (> $8 \mathrm{~mm}$ ), and inflammation. The two molars were vital with no periapical radiographic changes. After explaining treatment options to the patient (including extraction), the patient elected to have glass ionomer placed as an occlusive barrier over his furcation defects.

Following administration of local anesthesia using local infiltration of $2 \%$ Lidocaine with a concentration of 1:200,000 epinephrine, sulcular incisions were made. Vertical releasing incisions at distobuccal line angle of the second premolar were done, and full-thickness mucogingival flaps were reflected to expose all three furcation entrances (Figures 1 and 2).

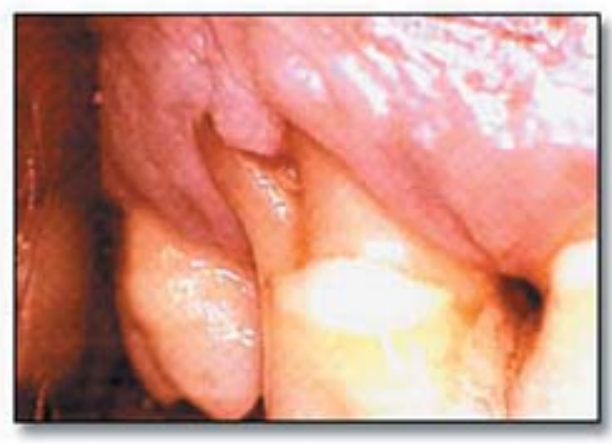

Figure 1. Pre-operative view of the right maxillary first molar with Class III furcation defects. 
The area was debrided, scaled and root planed using curettes and ultrasonic scalers. The area was irrigated with $0.2 \%$ chlorhexidine gluconate solution to disinfect the area. Due to the extent of the furcal defects and the poor chances of regenerating enough hard tissue support using traditional membrane therapy, an occlusive barrier using a glass ionomer was used to 'fillin' the furcations and prevent a recurrence of bacteria and/or debris accumulation into the furcation, thus, resulting in a periodontal abscess. Also, by reducing the concavities of the furcations, home care would be easier. The glass ionomer was placed using a plastic instrument in all three furcations, and the excessive material was removed with No. 15 B.P. blade (Figure 3).

The flaps were replaced using 4-0 directinterrupted silk sutures. The patient was advised to use $0.2 \%$ chlorhexidine gluconate mouth rinse twice daily for two weeks. The patient was provided with postoperative and home care instructions. The patient was prescribed antibiotics (amoxicillin $500 \mathrm{mg}$, three times daily for seven days) to reduce the risk of infection post operatively. Sutures were removed after seven days. Patient returned weekly for the first month for post surgical evaluation and reinforcement of plaque control. The patient was seen at three and six month intervals for supportive periodontal therapy. After one year post-operatively, teeth were re-evaluated for the following clinical parameters: tooth mobility, probing depth, bleeding on probing, and plaque levels. There was only Grade I mobility, $<5 \mathrm{~mm}$ probing depth, no bleeding on probing, and a plaque record of $10 \%$. Best of all, the patient was asymptomatic. The teeth were in function and did not experience any abscess or discomfort (Figure 4).

\section{Case 2}

A 45-year old female patient presented with Class III furcation defects (Hamp et al. $)^{1}$ involving all three furcations in the left maxillary first molar with a "poor to hopeless" prognosis, based on the clinical parameters of Grade II mobility, $>8 \mathrm{~mm}$ probing depth, inflammation, and no periapical radiographic changes. After explaining treatment options to the patient, including extraction, patient elected to have glass ionomer placed as an occlusive barrier over her furcation defects.

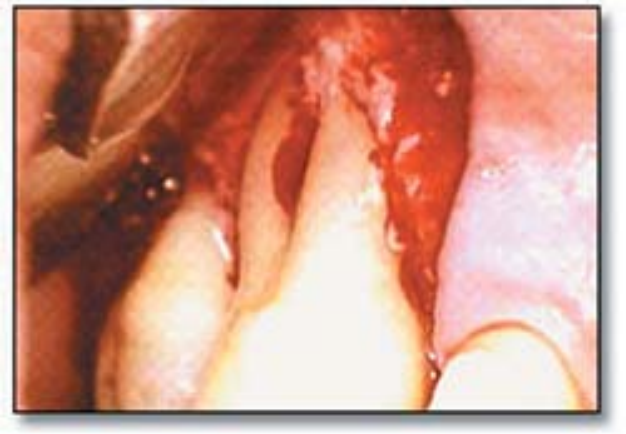

Figure 2. Buccal furcation defect following debridement.

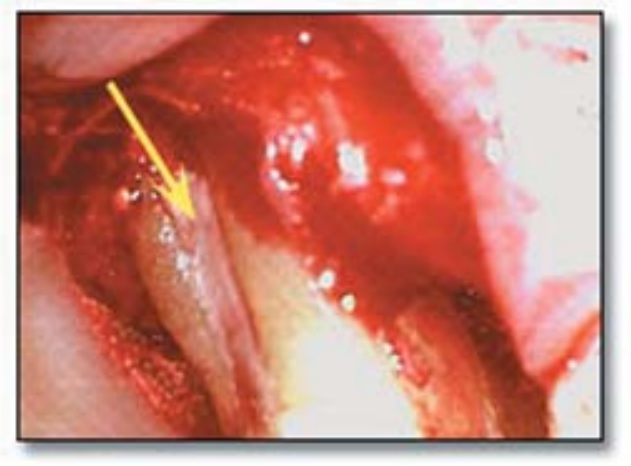

Figure 3. Buccal furcation defect restored with glass ionomer.

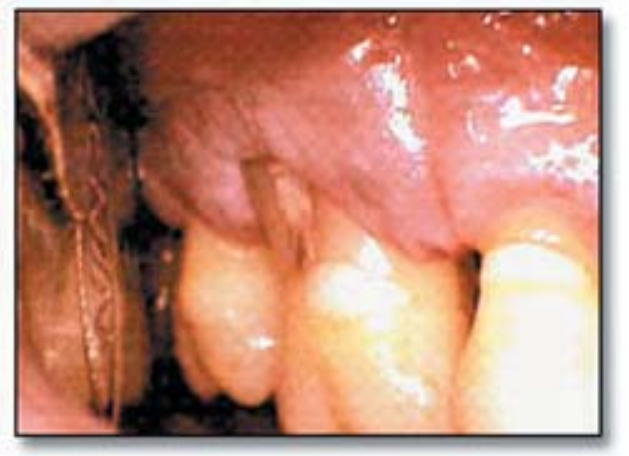

Figure 4. One year following view. Discoloration of the sealant in the furcation is due to staining.

Following administration of local anesthesia using local infiltration of $2 \%$ Lidocaine with a concentration of 1:200,000 epinephrine, sulcular incisions were made. Vertical releasing incisions at distobuccal line angle of the second premolar were done, and full-thickness mucogingival flaps were reflected to expose all three furcation entrances (Figures 5 and 6). 
The area was debrided, scaled and root planed using curettes and ultrasonic scalers. The area was irrigated with $0.2 \%$ chlorhexidine gluconate solution to disinfect the area. Glass ionomer was used to 'fill-in' the furcations (Figure 7). The flaps were replaced using 4-0 direct-interrupted silk sutures (Figure 8). The patient was advised to use $0.2 \%$ chlorhexidine gluconate mouth rinse twice daily for two weeks. The patient was prescribed antibiotics (amoxicillin $500 \mathrm{mg}$, three times daily for seven days) to reduce the risk of infection post operatively. Sutures were removed after seven days.

Patient returned weekly for the first month for post surgical evaluation and reinforcement of plaque control. Patient was seen at three and six months for supportive periodontal therapy. After one year post-operatively, the tooth was reevaluated and there was only Grade I mobility, $<5 \mathrm{~mm}$ probing depth, no bleeding on probing, and a plaque record of $10 \%$. The tooth was in function and did not experience any abscess or discomfort.

\section{Discussion}

Three maxillary molars that received glass ionomer restorations were functional and asymptomatic, and the patients were experiencing no adverse problems one year after the restorations were placed. The results of these two case reports illustrates the long-term prognosis that a traditionally hopeless maxillary molar can be improved by using an occlusive barrier, such as a glass ionomer restoration. Not only does the barrier seal the furcation entrance from epithelial, bacterial, and food debris invasion but may enable easier home care due to the reduced surface area of the furcation left to clean.

The use of a glass ionomer to regenerate the attachment apparatus in the treatment of advanced furcation involvement was not the goal of the treatment. There was no intention to regenerate any tissue, hard or soft. The goal of selecting this mode of therapy was simply to retain hopeless maxillary molars with advanced furcation defects.

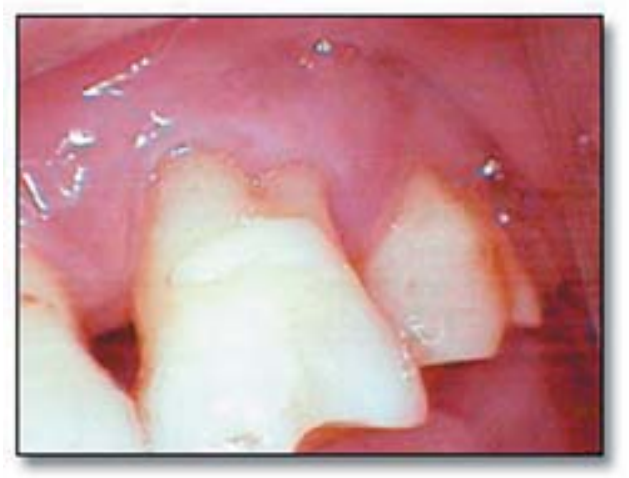

Figure 5. Pre operative view of left maxillary first molar with Class III furcation defects.

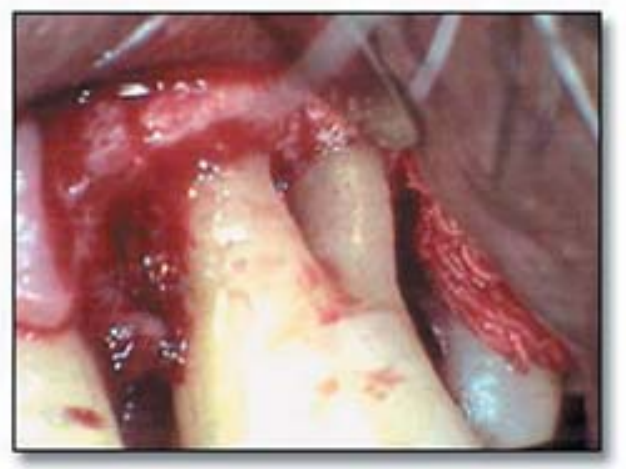

Figure 6. Buccal furcation defect following debridement.

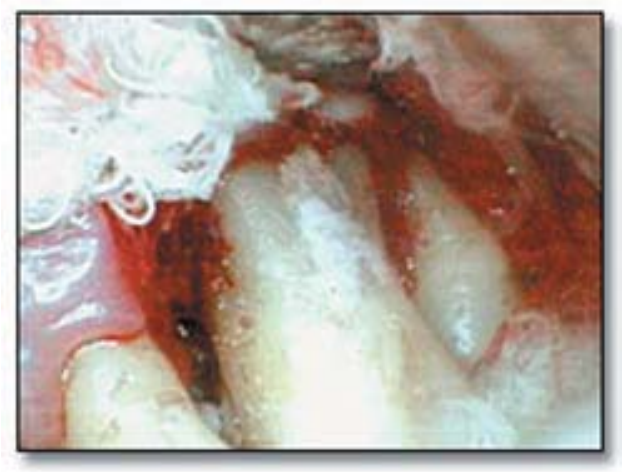

Figure 7. Buccal furcation defect restored with glass ionomer.

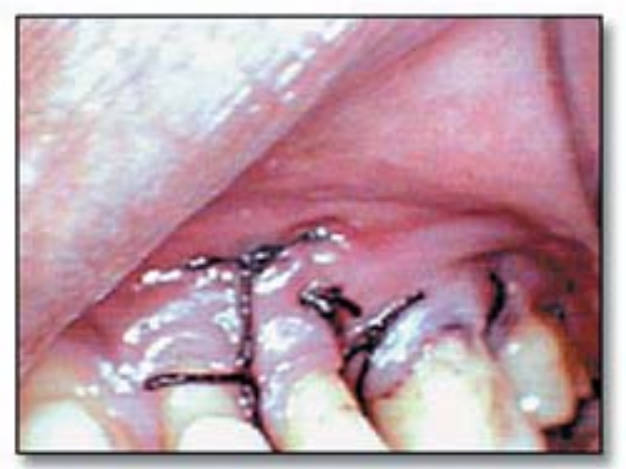

Figure 8. Post operative view. 


\section{Conclusion}

Potential advantages of an occlusive barrier such

as glass ionomer include:

- Ease of placement

- Does not require a suture for stability

- Elimination of a second stage procedure for retrieval of the membrane since it is permanently bonded

- Long junctional epithelial attachment to the glass ionomer ${ }^{22}$

- Does not require complete coverage by the gingival flap
- Bacteriostatic due to fluoride release ${ }^{27}$

- Lower cost

To potentially determine a greater clinical significance, studies with a larger sample size and control must be done. Within the limitations of these case reports, it can be concluded a glass ionomer restorative material may be effective as an occlusal barrier when treating maxillary molar Class III furcation defects.

\section{References}

1. Hamp SE, Nyman S, Lindhe J. Periodontal treatment of multirooted teeth. Results after 5 years. J Clin Periodontol 1975; 2:126-135.

2. Pearlman BA. Long-term periodontal care: A Comparative retrospective survey. J Periodontol 1993; 64:723-729.

3. Hirschfeld L, Wasserman B. A Long-term survey of tooth loss in 600 treated periodontal patients. J Periodontol 1978; 49:225-237.

4. Goldman MT, Ross IF, Goteiner D. Effect of periodontal therapy on patients maintained for 15 years or longer. A retrospective study. J Periodontol 1986; 57:347-353.

5. Friedman N. Mucogingival surgery: The apically repositioned flap. J Periodontol 1962; 33:328-340.

6. Langer B, Stein SD, Wagenberg B. An evaluation of root resections. A ten year study. J Periodontol $1981 ; 52: 719-722$.

7. Erpenstein H. A 3 year study of hemisectioned molars. J Clin Periodontol 1983;10:1-10.

8. Hellden LB, Elliot A, Steffensen B, et al. The prognosis of tunnel preparations in treatment of Class III furcations. A follow-up study. J Periodontol 1989; 60:182-187.

9. Pontoriero R, Lindhe J, Nyman S, et al. Guided tissue regeneration in degree II furcation involved mandibular molar. J Clin Periodontal 1988; 15: 247-254.

10. Lekovic V, Kenney EB, Carranze FA. Evaluation of guided tissue regeneration in class II furcation. A clinical re-entry study. J Periodontal 1989; 60: 694-698.

11. Melloning JT, Seamons BC, Gray JL, et al. Clinical evaluation of guided tissue regeneration in the treatment of grade II molar furcation invasions. Int J Periodontics Restorative Dent 1994; 14: 255-271.

12. Yukna CN, Yukna RA. Multi-center evaluation for guided tissue regeneration in human class II furcations. J Periodontal 1994; 65:1037-1045.

13. Wallace SC, Gellin RG, Miller M, et al. Guided tissue regeneration with and without freeze-dried bone mandibular class II furcation invasions Int J Periodontics Restorative Dent 1994; 14:255-271.

14. Andergg C, Martin S, Gray J, et al. Clinical evaluation of the use of decalcified freeze-dried bone allograft with guided tissue regeneration in the treatment of molar furcation invasions. J Periodontal. 1991; 62:264-268.

15. Rosen PS, Marks MH, Bowers GM. Regenerative therapy in the treatment of class II furcation. Int $\mathrm{J}$ Periodontics Restorative Dent 1997;17:517-527.

16. Simonpietri JJ, Navaes AB Jr, Batista EL Jr, et al. Guided tissue regeneration associated with bovine-derived anorganic bone in mandibular class II furcation defects. 6 month results of reentry J Periodontal 2000; 71:904-911.

17. Pontoriero R, Lindhe J. Guided tissue regeneration in the treatment of degree III furcation defects in maxillary molar. J Clin Periodontol 1995; 22:810-812.

18. Van Swol RL, Eslami A, Sadeghi EM, et al. A new treatment for furcation defects involving strategic molars. Int J Periodontics Restorative Dent 1989; 9:185-195. 
19. Anderegg CR. The treatment of Class III maxillary furcations using a resin-ionomer. A Case report. J Periodontol 1998; 69:948-950.

20. Anderegg CR, Metzler DG. Relation of multi-rooted teeth with Class III furcation lesion utilizing resins. Report of 17 cases. J Periodontol 2000; 71:1043-1047.

21. Fowler EB, Breault LG. Failure of resin -ionomers in the retention of multi-rooted teeth with Class III furcation involvement. A rebuttal case report. J Periodontol 2001; 72:1084-1091.

22. Scherer W, Dragoo MR. New clinical applications for resin-ionomer. Practical Periodontics Aesthetic Dent 1995; 7(1 Suppl.):1-4.

23. Dragoo MR. Resin-ionomer and hybrid-ionomer cements: Part II. Human clinical and histologic wound healing responses in specific periodontal lesions. Int J Periodontics Restorative Dent 1997; 17:75-87.

24. White C Jr. Repair of root resorption lesion. A case report. J Periodontol 1998; 69:596-600.

25. Breault LG, Fower EB, Primack PD. Endodontic perforation repair with resin-ionomer: $A$ case report. J Contemporary Dent Practice [serial online]. Fall 2000;number 4. Available at: http://www.thejcdp.com.

26. Breault LG, Fower EB, Lyons JC. Subgingival restorations with resin-ionomer: A periodontal alternative. Compendium Continuing Educ Dent 2000; 21:733-1047.

27. Smith D. Glass ionomer cements. A prospective symposium on esthetic restorative material. Chicago: American Dental Association. ADA council on Dental Materials. Instruments and Equipment: 1993:49-58.

\section{About the Authors}

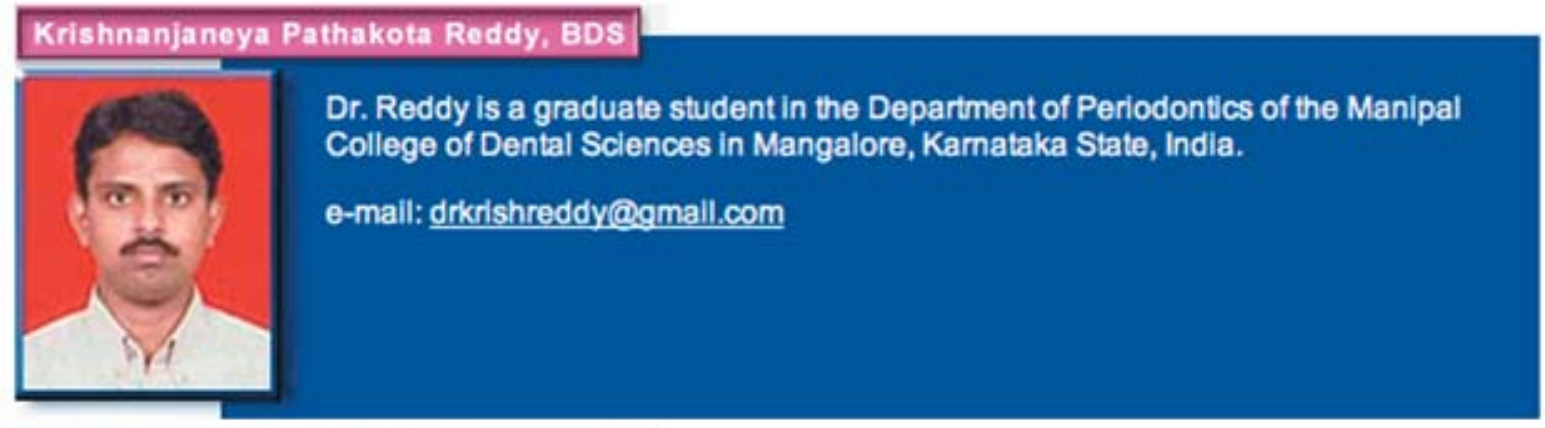

\section{Dillip Gopinath Nayak, MDS}

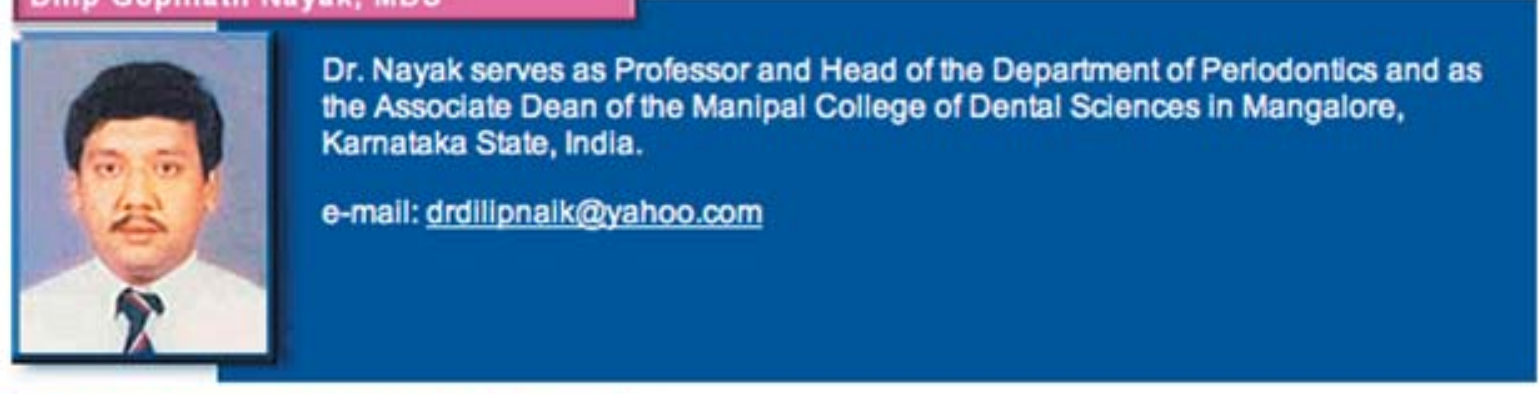

\section{Ashita Sadananda Uppoor A, MDS}

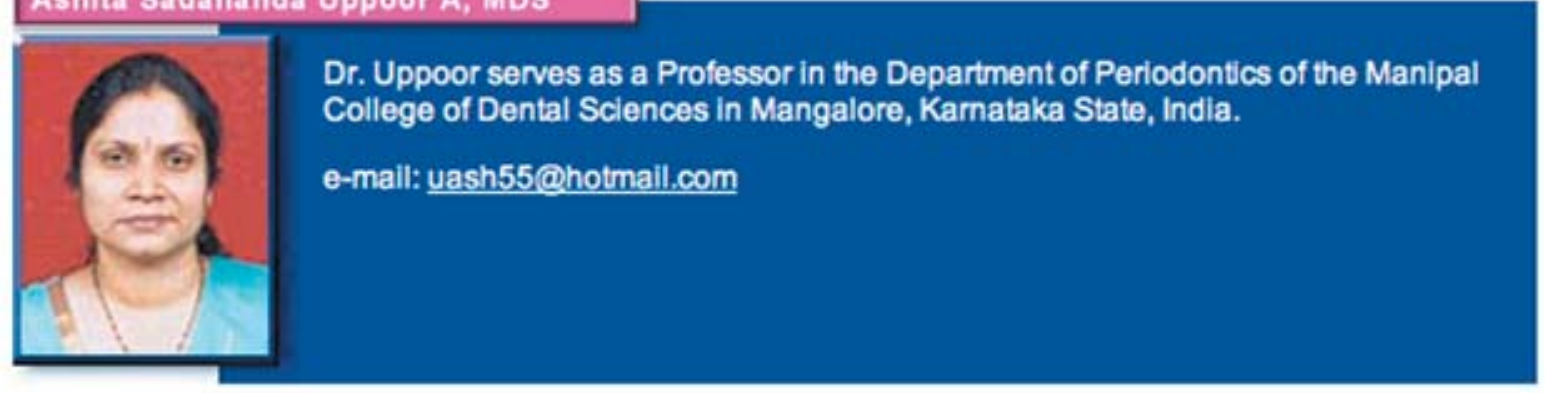

